\title{
Prevalence of Parasitic Infections among School Children in Bhaili, Durg, Chhattisgarh, India
}

\author{
Dhruba Hari Chandi ${ }^{*}$ and Sucheta J. Lakhani ${ }^{2}$ \\ ${ }^{1}$ Department of Microbiology, CCM Medical College Kachandur, Durg (CG), India \\ ${ }^{2}$ Department of Microbiology, SBKS Medical Institute and Research Centre, Piparia, India \\ *Corresponding author
}

\begin{tabular}{|l|}
\hline Ke y w o r d s \\
$\begin{array}{l}\text { Prevalence, School } \\
\text { children, Specimen, } \\
\text { Intestinal parasites }\end{array}$ \\
\hline Article Info \\
\hline $\begin{array}{l}\text { Accepted: } \\
\text { 12 August } 2018 \\
\text { Available Online: } \\
\text { 10 September } 2018\end{array}$ \\
\hline
\end{tabular}

\section{A B S T R A C T}

In developing countries including India intestinal parasitic infection is a major health problem. From different parts of the country many studies have been done. However, very few studies have been done from our area i.e. Durg, Chhattisgarh. About 2 billion people are infected with parasite globally. Children are most affected by parasite although it affected in all age group. Children become prime victim who affect their physical and mental development, ability to learn and school attendance. The present study was conducted in the Department of Microbiology, CCMMC, Bhaili, Durg Dist. Chhattisgarh; India. The objective of this study was to evaluate prevalence of parasitic infection among school children and their association with socio- demographic, environmental and behavioral habits of school children. The specimen was selected randomly. This study was conduct among 250 children (6-15 years of age) from the above school. Stool sample were collected and brought immediately to the microbiology laboratory at department of microbiology for processing. The specimens were examined by both macroscopically and microscopically for the presence of parasite. Parasitological standard examination methods were followed. Out of total 250 stool sample was collected from school children in this study, 160 were male and 90 were female. A total of 78 were positive for one or more parasite. Out of total positive $53.9 \%$ were protozoan, $38.5 \%$ were helminthes and $7.7 \%$ were mixed type. Entamoeba histolytica $38.5 \%$ and Ascaris lumbricoides $19.2 \%$ were the commonest protozoan and helminthes respectively. The other parasite found were Giardia lamblia $19.2 \%$, Hookworm 10.3\%, Taenia spp 5.1\%. Multiple parasitisms were found in $7.7 \%$ children. The present study shows $31.2 \%$ parasitic infection which is still important health problems in our region. Health awareness program, personal hygiene, hand washing as well as uses of sanitary latrine and treatment of food to reduce the incidence of parasitic infection should be carried out in these communities.

\section{Introduction}

Form the time of Antony van Leeuwenhoek, a Dutch draper of Holland, who observes sundry material by using single lensed microscope of his design, which referred to as animalcules.
For centuries to this era parasitic infection have been causing high mortality and morbidity to mankind worldwide especially in the developing countries like India (Sucheta et al., 2013). In developing countries, intestinal parasitic infections are major health problem 
among children worldwide is aggravated by poverty, malnutrition, poor health and climate (Shakya et al., 2012). Parasitic infections are affected in all age group whereas children are most affected (Markell and Voge, 1965; Steketee, 2003). Children living in low poverty are probably suffering from parasitic infection of rural communities among poorest sector (Tripathi Kiran et al., 2014). Intestinal parasitic infection has become prime victim in children, which affect their physical and mental development, ability to learn and school attendance. (Agrawal et al., 2012)

All over the world, especially developing countries parasitic infection is responsible for causing morbidity and mortality. Therefore it is known as 'cancers of developing countries (Tiwari et al., 2013). According to WHO approximate over 270 million pre-school children and over 600 million of school children are living in parasitic transmitted area and in need of treatment and prevention. In developing countries, about 750 million episodes of diarrhea occur which results in five millions death (Bhandari et al., 2011; Singh et al., 2010). Parasitic infections are major problem in India like other developing countries. Globally reported commonest parasitic infection are Ascaris lumbricoides, Hookworm, Enterobius vermicularis, Trichuris trichiura, Entamoeba histolytical dispar and Giardia lamblia (Misra Shobhaa et al., 2013; Supriya Panda et al., 2012). In India overall prevalence of parasitic infection varies from about $13 \%$ to $68 \%$ (Swapna Kotian et al., 2014). In developing countries high prevalence of intestinal parasitic infections are associated with factors like low literacy rate, poverty, poor hygiene, lack of potable water and climate area. There are still many communities or localities for which epidemiological information is still not available although there are many studies have been conducted on prevalence of parasitic infection among school children.
However monitoring of parasitic infection and their factors is necessary for approaching the problem because they reflect health education of the community which provides basic data for control for future infection.

The objective of this study was to evaluate prevalence of parasitic infection among school children of Bhaili, Durg district of Chhattisgarh and their association with sociodemographic, environmental and behavioral habits of school children.

\section{Materials and Methods}

This cross sectional study was conducted in Sahhashikaya Higher Secondary School located in Bhaili, Durg district of Chhattisgarh state located in central east India after obtaining permission from respective authority. The specimen was selected randomly. This study was conduct among 250 children (6-15 years of age) from the above school. Considering the subject purpose and procedure of study, all teachers, children and their parents were informed through the principle of school before collecting the sample.

Explaining in conversational language small presentation, projecting the picture of various forms of parasites and their disease were shown with advantage of stool examination. The procedure for stool collection was thoroughly explained and clean plastic stool containers were distributed to every student on the day before specimen collection with identification number and name. Next day the stool sample were collected and brought immediately to the microbiology laboratory at department of microbiology for processing.

Macroscopic Examination: All stool samples were examined macroscopically for presence of blood, mucus, adult worms, segments of tapeworm, and larvae. The consistency of 
stool as formed, loose or watery or soft with color and odor were noted.

Microscopic Examination: All stool samples were examined by direct microscopic examination. Saline and Iodine wet mount were performed for the presence of parasitic cysts, trophozoites and ova and larva and also presence of leukocytes and erythrocytes.

Concentration technique as Formal ether concentration method was also done and again the sediments were examined by microscopically again (wet mount and iodine preparation).

After finding the parasitic ova in stool sample Mac master slide method was also performed for counting parasitic ova per gram. Positive stool sample with presence of parasites were informed and referred to pediatric OPD of our hospital for treatment.

\section{Results and Discussion}

Total 250 stool samples were collected from school children of age group 6 to 15 years in a clean, dry screw capped plastic container. Collected stool samples were examined by wet mount (saline and iodine wet mount preparation method) and also by formal ether concentration method. Out of total 250 samples 160 were male and 90 were female school going children were included in this study. Total 78 (31.2\%) stool samples intestinal parasites were found out of 250 samples in which $46(28.75 \%)$ were male and $32(35.6 \%)$ were female as shown in table 1 and 2. The prevalence of parasitic infection was significantly higher among female children $32(35.6 \%)$ out of 90 than male children $46(28.75 \%$ ) out of 160 (Table 2).

The chi-square statistic is 1.2428 . The $p$-value is 0.264929 . The result is not significant at $p<$ 0.05 .
According to the age highest infection rate was significantly observed in children between 5 to 10 years $(41.1 \%)$, followed by $10-15$ years $(25.6 \%)$ as shown in table 3 .

The chi-square statistic is 6.4352 . The $p$-value is 0.011188 . The result is significant at $p<$ 0.05 .

42(53.9\%) Protozoa and 30(38.5\%) helminthes and 6(7.7\%) mixed (both protozoa and helminthes) were detected out of total positive for parasite. E. histolytica (38.5\%), G. lamblia (19.2\%), Ascaris lumbricoides (19.2\%), Hookworm (10.3\%) and Taenia spp $(5.1 \%)$ were commonest protozoan and helminthes respectively as shown in table 4 .

Especially in developing countries parasitic infection represents relevant clinical problems which are responsible for mortality and morbidity in children and adults with variation from region to region, communities and ethnic group and even seasonal variation (Peruzzi et al., 2006). Because of changes in life style and social behavior in communities, prevalence of parasitic infection may vary.

Different epidemiological studies will provide understanding health status of community (Aher and Kulkarni, 2011).

In this study, the prevalence of parasitic infection among school children was found to be $31.2 \%$. This finding was line up with a study conducted in school children of rural community in India was $30.4 \%$ by Aher and Kulkarni (2011). However high prevalence of intestinal parasitic infection have reported about $42.14 \%, 50 \%$ to $65 \%$ among school children as studies carried out in different parts of India Dr. Sucheta et al., (2013), Chakma et al., (2000) and Sugunan et al., (1996). According to the study of Bora et al., prevalence was found to be $31.5 \%$ which was similar to this study (Bora et al., 2006). 
Table.1 Number and percentage of students showing the positive of intestinal parasite

\begin{tabular}{|c|c|c|}
\hline No. of students & Result & Percentage (\%) \\
\hline $\mathbf{7 8}$ & Positive & 31.2 \\
\hline 172 & Negative & $\mathbf{6 8 . 8}$ \\
\hline 250 & Total & 100 \\
\hline
\end{tabular}

Table. 2 Showing the positive for parasite according to sex

\begin{tabular}{|c|c|c|c|c|}
\hline Sex & Total & Positive & Percentage (\%) & P-value \\
\hline Male & 160 & 46 & 28.7 & 0.26 \\
\hline Female & 90 & 32 & 35.6 & \\
\hline Total & 250 & 78 & 31.2 & \\
\hline
\end{tabular}

Table.3 Showing the prevalence for parasite according to age

\begin{tabular}{|c|c|c|c|c|}
\hline Age group & Total Number & Positive & Percentage (\%) & P-value \\
\hline 5-10 Years & 90 & 37 & 41.1 & 0.01 \\
\hline 10-15 Years & 160 & 41 & 25.6 & \\
\hline
\end{tabular}

Table.4 Showing prevalence of parasites species in children

\begin{tabular}{|c|}
\hline Type of parasite \\
Protozoa \\
\hline Entamoeba histolytica \\
\hline Giardia lamblia \\
\hline Helminthes \\
\hline Ascaris lumbricoides \\
\hline Taenia spp \\
\hline Hookworm \\
\hline Mixed(Both Protozoa and Helminths) \\
\hline Total \\
\hline
\end{tabular}

\begin{tabular}{|c|c|}
\hline Total Positive & Percentage \\
\hline $\mathbf{4 2}$ & $\mathbf{5 3 . 9}$ \\
\hline 30 & 38.5 \\
\hline 15 & 19.2 \\
\hline $\mathbf{3 0}$ & $\mathbf{3 8 . 5}$ \\
\hline 15 & 19.2 \\
\hline 4 & 5.1 \\
\hline 8 & 10.3 \\
\hline 6 & 7.7 \\
\hline $\mathbf{7 8}$ & $\mathbf{3 1 . 2}$ \\
\hline
\end{tabular}

Fig.1, 2, and 3 Shows as E. histolytical, Ascaris lumbricoides and G. lamblia respectively

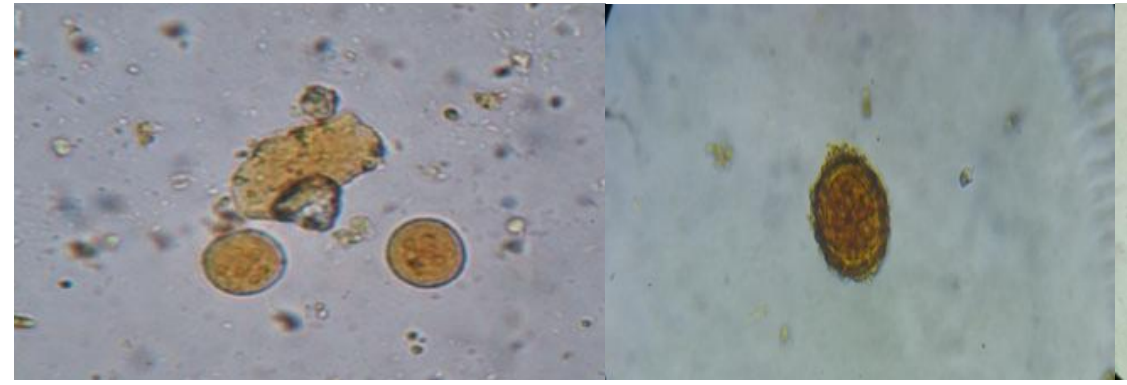

Fig.1
Fig.2

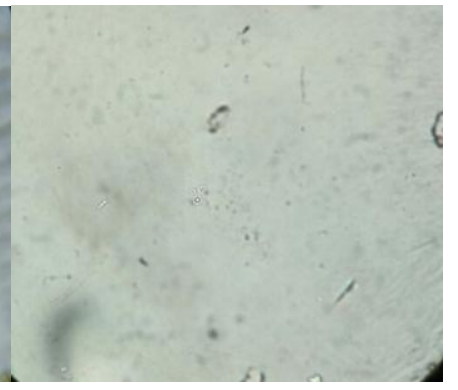

Fig.3 
Study conducted by Rashid et al., prevalence was 22.3\% (Rashid et al., 2011) whereas study of Dr. Sucheta et al., prevalence in school going children in Vadodara was 42.14\% (Sucheta et al., 2013) which was quite lower and higher than this study. However in study of Dambhare et al., (2010) intestinal parasitic infection was found only $7.56 \%$ of school children in rural area. The distribution over a wide area might be due to behavioral and social factors affecting the degree of infection.

In this study, prevalence of parasitic infection was slighter higher in female $35.6 \%$ than males $28.75 \%$ which is quite similar to study of Vincent P. Gyang et al., (2017) and Panda et at (2012) In the study of Shakya et at (2012) and Tamirat et al., (2017) also shows higher prevalence rate in females than male. Where as in the study of Dr. Sucheta et al., (2013) shows that there was no significant prevalence in respect to gender.

Base on the age of children, highest prevalence was found among aged 5-10 years followed by $10-15$ years. This shows similar to the result of previous studies of Khanal et al., (2011), Shakyae et al., (2012). This higher prevalence in age group 5-10 years may be due to unhygienic behavior, lack of sanitation and lack of proper care of children by their parents.

In this study Helminthes was dominating by Protozoa was similar to most of the findings from India. E. histolytica $(38.5 \%)$ was the commonest parasite from protozoa whereas Ascaris lumbricoides (19.2\%) was the commonest helminthes found in this study which was quite similar to the other studies from other parts of the India and from around the world. Study of Gelaw et al., E. histolytica found as commonest protozoan (Gelaw et al., 2013). Other studies conducted in different areas revealed different species which are found more prevalent as study of Dambhare et al., (2010), Marothi and Singh et al., (2011), Ragunathan et al., (2010), Bisht et al., (2011), Davane et al., (2012), Rashid et al., (2011). In this study Giardia lamblia $19.2 \%$ which was alter in compared to other study found in children from India Dr. Sucheta et al., (2013), Sehgal et al., (2010) and Aher et al., (2011). Ascaris lumbricoides $19.2 \%$ followed by Hookworm $10.3 \%$, Taenia spp $5.1 \%$. Multiple parasites was detected in $7.7 \%$ of children which was less as comparing to the other studies Ouattara et al., (2010), Magar et al., (2011) and Rituparna et al., (2017).

According to the guideline of US Department of Health 2013, suggest that people from developing countries of Africa and Asia are highly susceptible to parasitic infection, which may cause seriously illness as they may lead to even death (UD Department of Health and Human Services, 2013).

The present study shows $31.2 \%$ parasitic infection which is still important health problems in our region. This prevalence may be due to poor personal hygiene, poor sanitation, illiterate about health education poor socioeconomic condition and other factors. Therefore, health awareness program, personal hygiene, hand washing as well as uses of sanitary latrine and treatment of food to reduce the incidence of parasitic infection should be carried out in these communities. More and more work to be carried out still to reach more of these communities.

\section{References}

Agrawal PK, Rai SK, Khanal Lk, Ghimire G, Banjara MR, Singh A. Intestinal Parasitic infection among patients attending Nepal Medical College Teaching Hospital, Kathmandu, Nepal. Nepal Med Coll J 2012; 14(2): 80-83. 
Aher A, and Kulkarni S. prevalence of intestinal Parasites in School going children in a rural community. Int J BioMed Res 2011; 2(12): 605-7.

Bhandari N, Kausaph V, NEupane GP. Intestinal Parasitic Infection among school age children, 2011. J Nepal Res Council; 9: 30-2.

Bhattacharya Rituparna, P Bhattacharya, U K Paul, A Bandyopadhyay. Prevalence of Intestinal Parasites in a Tertiary Care Hospital in Rural Bihar. International Journal of Scientific Study | March 2017 | Vol 4 | Issue 12: 89-93.

Bisht D, Verma AK, Bharadwaj HH. Intestinal parasitic infestation among children in a semi-urban Indian population. Trop Parasitol 2011; 1:104-7

Bora D, Meena VR, Bhagat h, Dhariwal AC, Shivlal. Soil transmitted helminthes. Prevalence in school children of Pauri Garhwal district, Uttaranchal State. J Commun Dis 2006; 38: 112-4.

Chakma T, Rao PV, Tiwary RS. Prevalence of anaemia and worm infestation in tribal areas of Madhya Pradesh. J Indian Med Assoc. 2000 Sep; 98(9): 567, 570-1.

Dambhare D G, Bharambe M S, Garg B S. Intestinal Parasites Prevalence and Related Factors among School Children in the Rural Area of Central India. $J$. Commun. Dis. 42 (4) 2010: 281-286

Davane MS, Suryawanshi NM, Deshpande KD. A prevalence study of intestinal parasitic infections in a rural hospital. Int J Recent Trends Sci Technol 2012; 2:1-3.

Gelaw A, Anagaw B, Nigussie B, Silesh B, Yirga A and Alem $\mathrm{M}$ et al., Prevalence of intestinal parasitic infections and risk factors among school children at the University of Gondar Community School, Northwest Ethiopia: a cross-sectional study. BMC Public Health 2013; 13: 30414.

Khanal LK, Rai SK, Khanal PR and Ghimire G (2011). Status of intestinal parasitosis among hospital visiting patients in Deukhury valley, Dang, Nepal. Nepal Med Coll J 13: 100-102
Magar DT, Rai SK, Lekhak B and Rai KR (2011). Study of parasitic infection among children of Sukumbasi basti in Kathmandu Valley. Nepal Med coll J 13: 7-10.

Markell EK, and Voge M. Medical Parasitology. Academic Medicine 1965; 40(7):719.

Marothi Y, Singh B (2011) Prevalence of intestinal parasites at Ujjain, Madhya Pradesh, India: five year study. African J Microbiol Res 5(18):2711-2714

Misra Shobhaa*, Duttaroy Bithika b, Shroff Bhavesha. The prevalence of intestinal parasitic infections in the urban slums of a city in Western India. Journal of Infection and Public Health (2013) 6, $142-149$

Ouattara M, N'guéssan NA, Yapi A, N'goran EK. Prevalence and spatial distribution of Entamoeba histolytica/dispar and Giardia lamblia among schoolchildren in Agboville area (Côte d'Ivoire). PLoS Negl Trop Dis 2010; 4 Suppl 1:e574.

Peruzzi S, Gorrini C, Piccolo G, Calderaro A, Dettori G, Chezzi C. Prevalence of intestinal parasites in the area of Parma during the year 2005. Actam Biomed 2006; 77: 147-151.

Ragunathan L, Kalivaradhan SK, Ramadass S, Nagaraj M, Ramesh K. Helminthic infections in school children in Puducherry, South India. J Microbiol Immunol Infect 2010; 43: 228-32.

Rashid MK, Joshi M, Joshi HS and Fatemi K. Prevalence of intestinal parasites among school going children in Bareilly District. NJIRM; 2011, 2(1): 35-37

Sehgal R, Reddy GV, Verweij JJ, Rao A. Prevalence of intestinal parasitic infections among school children and pregnant women in a low socio-economic area, Chandigarh, North India. RIF. 2010; 1(2):100-3.

Shakya B, Shrestha S, MAdhikarmi NL, Adhikari R (2012). Intestinal Parasitic Infection among School Children. J Nepal Health Res Counc 10: 20-3 
Singh C, Zargar SA, Masoodi I, Shoukat A, Ahmad B. Predictors of intestinal parasitosis in school children of Kashmir: a prospective study. Tropical Gastroenterology 2010; 31(2):105-7.

Steketee RW. Pregnancy, nutrition and parasitic diseases. The Journal of nutrition 2003; 133(5):1661S-7S.

Sucheta J. Lakhani Dr., Mrs. Radhika RanaKhara, Dr. Sunanda Joshi and Dr. Smriti Vasisht. Intestinal parasitic Infestation among school children in Piparia village, Vadodara District. International Journal of Scientific Research. Vol: 2; Issue: 12 Dec 2013: 434-436.

Sugunan AP, Murhekar MV, Sehgal SC. Intestinal parasitic infestation among different population groups of Andaman and Nicobar islands. J Commun Dis. 1996 Dec; 28(4): 253-9.

Supriya Panda Dr., 2Dr.U.Dharma Rao, 3Dr.K.Rama Sankaram. Prevalence of Intestinal Parasitic Infections among School Children in Rural Area of Vizianagaram. IOSR Journal of Pharmacy and Biological Sciences (IOSR-JPBS) ISSN: 2278-3008. Volume 3, Issue 3 (Sep-Oct. 2012), PP 42-44.

Swapna Kotian, Munesh Sharma, Deepak Juyal, Neelam Sharma. Intestinal parasitic infection-intensity, prevalence and associated risk factors, a study in the general population from the Uttarakhand hills. International Journal of Medicine and Public Health, Oct-Dec 2014, Vol. 4, Issue 4: 422-425.

Tamirat Hailegebrie. Prevalence of intestinal parasitic infections and associated risk factors among students at Dona Berber primary school, Bahir Dar, Ethiopia. Hailegebriel BMC Infectious Diseases (2017) 17: 362.

Tiwari BR, Chadhury R, Adhikari N, Jayaswal SK, Poudel TP and Rijal K,. Prevelence of intestinal parasitic infections among school children of Dadeldhura District. JHAS, 2013; 3: 14-6.

Tripathi Kiran, Nema Shashwati, Bankwar Vishal, Dhanvijay Ashok kumar. Intestinal Parasitic infections and Demographic status of school children in Bhopal region of Central India. IOSR Journal of Pharmacy and Biological Sciences (IOSR-JPBS). Volume 9, Issue 5 Ver. II (Sep -Oct. 2014), PP 83-87.

UD Department of Health and Human Services. Intestinal Parasite Guidelines for Domestic Medical Examination for Newly-arrived Refugees. New York: UD Department of Health and Human Services; 2013. p. 1-13.

Vincent P. Gyang, Ting-Wu Chuang, ChienWei Liao, Yueh-Lun Lee, Olaoluwa P. Akinwale, Akwaowo Orok, Olusola Ajibaye, Ajayi J. Babasola, Po-Ching Cheng, Chia-Mei Chou, Ying-Chieh Huang, Pasaiko Sonko, Chia-Kwung Fan. Intestinal parasitic infections: Current status and associated risk factors among school aged children in an archetypal African urban slum in Nigeria. Journal of Microbiology, Immunology and Infection (2017) xx, 1-8. Received 8 April 2016; received in revised form 8 August 2016; accepted 28 September 2016.

\section{How to cite this article:}

Dhruba Hari Chandi and Sucheta J. Lakhani. 2018. Prevalence of Parasitic Infections among School Children in Bhaili, Durg, Chhattisgarh, India. Int.J.Curr.Microbiol.App.Sci. 7(09): 19191925. doi: https://doi.org/10.20546/ijcmas.2018.709.233 